The interference with deep venous blood flow may be brought about by inexpert bandaging. The importance of a meticulous and practical bandaging technique has recently been re-emphasized (Fegan, 1971).

In addition, many patients feel that a bandaged limb should be 'rested'. Inactivity of the calf muscle pumps appreciably slows the rate of deep venous return. We give detailed instructions to our patients about increasing their activities, especially walking, during the period of treatment. We have not previously insisted that they walk 2 to 3 miles immediately following treatment, as do some clinics (Fegan, 1967) Nevertheless, it may be significant that in this case, almost immediately following treatment, the patient had a long car journey to return home. This subsequent inactivity would appear to have appreciably increased the risk of deep venous thrombosis.
References

FEGAN, W.G. (1963) Continuous compression technique of injecting varicose veins. Lancet, ii, 109.

FEgAN, W.G. (1967) Varicose Veins-Compression Sclerotherapy. Heinemann, London.

Fegan, W.G. (1971) The art of bandaging the lower limb? British Journal of Hospital Medicine, 5, 697.

FEgan, W.G. (1970) Personal communication.

Hoввs, J.T. (1968) The treatment of varicose veins. British Journal of Surgery, 55, 777.

LINSER, P. (1911) Quoted by DzIACzKowsKı, I. (1960) $\overrightarrow{0}$ Therapy of thrombophlebitis with Butazolidin. Polsik Tygodnik Lekarski, 14, 1911.

Linser, P. (1916) Veber die Konservative Behandlung dero Varium. Medizinische Klinik, 12, 897.

SIGG, K. (1952) Treatment of varicose veins and accom panying complications. Angiology, 3, 355 .

\title{
Pulmonary reaction to Furoxone
}

\author{
J. V. Collins \\ M.B., M.R.C.P.
}

\section{A. L. THOMAS \\ M.B., M.R.C.P.}

\section{Summary}

A patient is reported in whom an acute pulmonary reaction resulted from the ingestion of Furoxone (furazolidine), a member of the nitrofurantoin group of drugs. A positive lymphocyte transformation test to Furoxone was found. This is thought to suggest that Type IV (Gell \& Coombs, 1968) thymus dependent hypersensitivity may be implicated in such pulmonary reactions.

WHEN a patient develops what is suspected to be a hypersensitivity reaction to a drug, the problem of identifying the drug responsible becomes more difficult as the number and variety of drugs available for prescription increases. It has been shown that between $5-10 \%$ of patients admitted to hospital experience some toxic or hypersensitivity reaction to a drug (Reeves \& Trounce, 1971). Antibiotics, hypnotics and tranquillizers are the drugs most likely to produce such reactions (MacDonald \& Mackay, 1964). We report a patient in whom a respiratory illness complicated drug therapy for an unrelated condition.

Reprint requests to: Dr J. V. Collins, St Bartholomew's Hospital, London, E.C.1A 78E.

\section{Case history}

The patient, K.P., a man aged 56 years, was admitted to St Olave's Hospital on 23 March 19713 with a 12-day history of fever, rigors, generalized rash and night sweats associated with general malaise.: From September 1970, he had been complaining of severe low back pain, which after extensive investiga -3 tion was found to be due to osteomyelitis of $\mathrm{L} 3 / 4.0$ This was treated with a 5-week course of cloxacillin (3-chlorophenyl-5-methyl-4-isoxazolyl penicillin) until 11 February 1971. His back pain improved and his ESR fell. He travelled to Tangier for a convales응 cent holiday and 5 days later he developed nauseas and anorexia after meals, without vomiting or? diarrhoea. He returned to England on 28 February 1971 , and because of persistence of these symptoms he suspected that he had a gastro-intestinal infection 5 and treated himself with Furoxone (3-(5-nitrow furfurylideneamino)-2-oxo-oxazolidine) for 5 days finishing on 9 March 1971. 2 days later he becameo febrile with rigors and breathlessness. His back paino returned and on 11 March 1971 he took $500 \mathrm{mg}$ of ampicillin ( $\alpha$-amino benzyl penicillin). The followingo day he had a generalized urticarial scarlatiniforme rash. He changed immediately to Floxapen (flucloxa 
cillin) $500 \mathrm{mg}$ t.d.s., which he took for 11 days, the rash fading on the second day.

He was admitted to hospital on 17 May 1971 and on examination he was apyrexial, breathless on slight exertion and the only abnormal physical signs were splinter haemorrhages under the right thumb nail and tenderness over the 4th lumbar vertebra. Chest $\mathrm{X}$-ray on admission showed diffuse mottling throughout both lung fields (Fig. 1) which cleared 7 days later (Fig. 2).

Laboratory investigations on admission to hospital included:

Haemoglobin $=14.9 \mathrm{~g} / 100 \mathrm{ml}$, white blood count $=17,500 / \mathrm{mm}^{3}$, eosinophils $=1050 / \mathrm{mm}^{3}(6 \%)$, ESR $=22 \mathrm{~mm} / \mathrm{hr}$. Plasma proteins; total $-7.0 \mathrm{~g} / 100 \mathrm{ml}$, albumin $=3.7 \mathrm{~g} / 100 \mathrm{ml}$. Electrophoresis normal. Staph.-anti-streptolysin titre 1 unit (normal 0-2). Electrolytes normal. Blood urea $=38 \mathrm{mg} / 100 \mathrm{ml}$. MSU, sterile. Sputum for AFB and malignant cells, negative. Rose Waaler and Latex fixation, both negative. Agglutination tests for Brucella, Salmonella typhi, S. paratyphi A and B, negative. No pathogens isolated from stools. Bone marrow, normal. Kveim test, negative. Lymphocyte transformation test was carried out by Dr S. Alexander, using the method incorporating ${ }^{14} \mathrm{C}$ thymidine, described in detail elsewhere (Forman \& Alexander, 1972). The results showed a strongly positive reaction to Furoxone. Respiratory function tests were not available until after recovery, but then showed:

\begin{tabular}{lcc}
\hline & Test & Predicted \\
\hline FEV $_{1}$ (litres) & 3.0 & $3 \cdot 2$ \\
FVC (litres) & 3.5 & 3.5 \\
PEFR (1/min) & 600 & 550 \\
FER & $86 \%$ & - \\
\hline
\end{tabular}

Carbon monoxide transfer factor: TLCO $=22 \mathrm{ml} / \mathrm{mın}$ $\mathrm{mmHg}$ (predicted value, $29 \mathrm{ml} / \mathrm{min} / \mathrm{mmHg}$ ).

\section{Discussion}

It is known that Furadantin (1-(5-nitrofurfurylideneamino-hydantoin) may produce a toxic megaloblastic anaemia and pulmonary infiltration due to a hypersensitivity reaction. In the acute form of pulmonary reaction, cough, dyspnoea and fever often accompanied by myalgia and a maculo-papular rash may occur. Diffuse pulmonary shadows are seen on chest X-ray. Leukocytosis and eosinophilia may occur. After withdrawal of the drug, the condition quickly resolves, but a chronic form with insidious onset unassociated with fever may proceed to pulmonary fibrosis (British Medical Journal, 1969; Rosenow et al., 1968). The immunological basis for these reactions is thought to be a Type III reaction of Gell \& Coombs (Gell \& Coombs, 1968).

Furoxone (3-(5-nitrofurfurylideneamino)-2-oxooxazolidine) is an antibacterial agent of similar

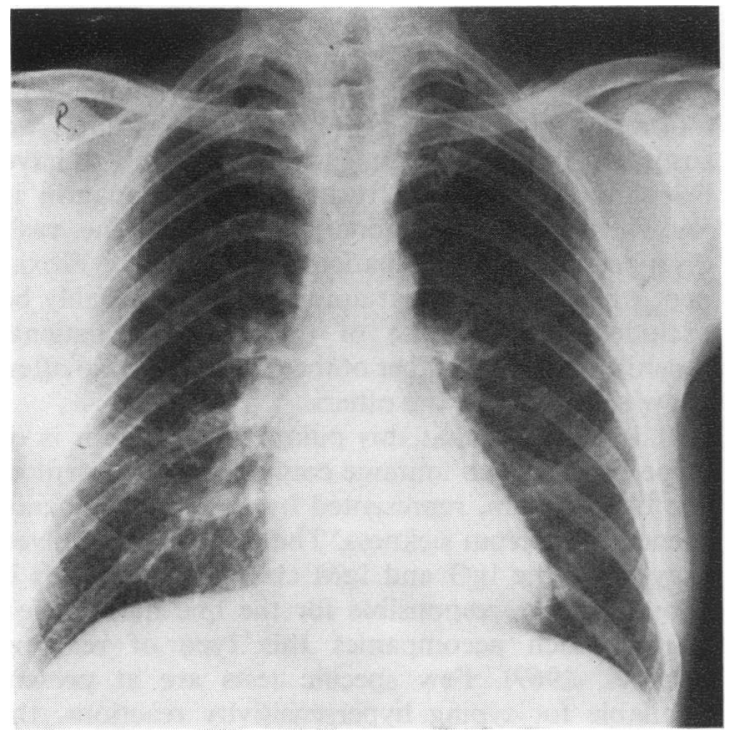

FIG. 1. Chest X-ray on admission.

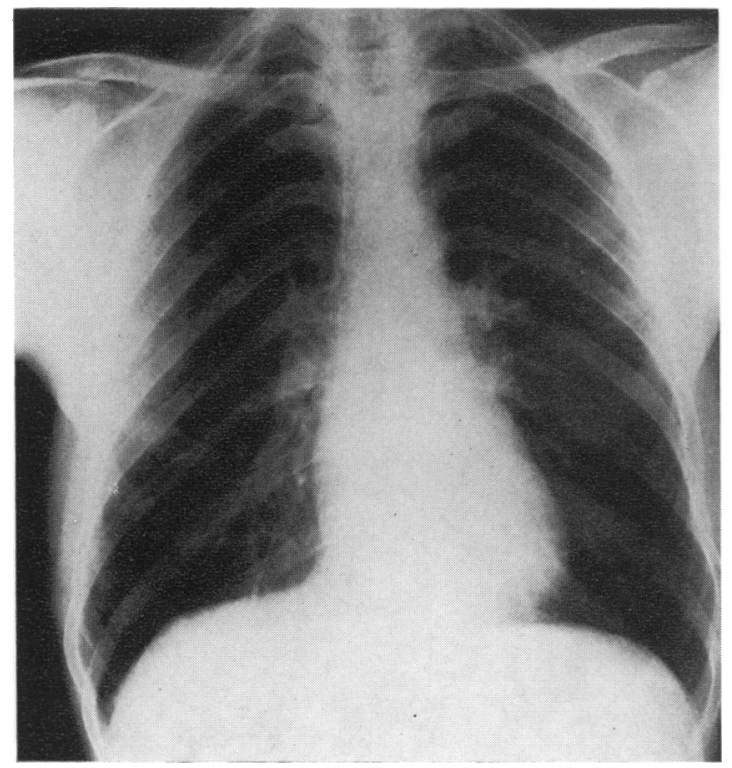

Fig. 2. Chest $\mathrm{X}$-ray 7 days after admission.

chemical structure to Furadantin, and it is known to cause maculo-papular, vesicular and urticarial skin eruptions (Kautz, 1960). It has been noted that the ingestion of alcohol in patients who are receiving the drug can bring about excessive skin flushing and dyspnoea similar to the reaction manifested by giving Antabuse (Kautz, 1960). No pulmonary effects have 
yet been recorded. The patient we reported presented with a febrile illness, breathlessness, urticaria and eosinophilia associated with diffuse pulmonary infiltration on chest X-ray. From these findings we suspected a drug reaction. Furoxone is likely to have been the cause, as the related drug Furadantin is known to cause pulmonary reactions. The rash disappeared while the patient was receiving Floxapen, which suggests that ampicillin can probably be excluded as the cause of the rash, for patients sensitized to one member of the penicillin group often show sensitivity to the others.

It is probable that this pulmonary reaction is of Type III, in which immune complexes are present in the bloodstream, represented by the Arthus phenomenon and serum sickness. The antibodies involved may be of the IgG and IgM classes. An arteritis is thought to be responsible for the fine mottling on $\mathrm{X}$-ray which accompanies this type of reaction (Davies, 1969). Few specific tests are at present available for typing hypersensitivity reactions, the lymphocyte transformation test used in our patient is usually taken as an in vitro measure of a potential in vivo delayed hypersensitivity response, Type IV hypersensitivity (Gell \& Coombs, 1968; Sarkany, 1967). Our findings of a positive lymphocyte transformation may perhaps indicate that the mechanisms underlying infiltration due to drugs of the Furadantin group may involve both Type III and IV reactions

\section{Acknowledgments}

We should like to thank Dr K. S. MacLean for permission? to publish this case report and Dr S. Alexander for carrying out the lymphocyte transformation studies.

\section{References}

British Medical Journal (1969) Pulmonary sensitivity tô nitrofurantoin. Annotation. British Medical Journal, 4, 704.

Davies, P.D.B. (1969) Drug-induced lung disease. Britisp Journal of Diseases of the Chest, 63, 57.

Forman, L. \& AlEXANDER, S. (1972) Nickel antibodieswi British Journal of Dermatology, in press.

Gell, P.G.H. \& Coombs, R.R.A. (1968) Clinical Aspects $\$$ Immunology, 2nd edn. Blackwell Scientific Publications Oxford.

KAUTZ, H.D. (1960) New and unofficial drugs. Journal ob American Medical Association, 172, 1932.

MacDonald, M.G. \& MackaY, B.R. (1964) Adverse drug్ reactions. Journal of American Medical Association, 1906 1071.

ReEves, W.G. \& Trounce, J.R. (1971) The problem of drug hypersensitivity. Guy's Hospital Reports, 120, 245.

Rosenow, E.C., Three, M.D., Richard, A., DE Remee, M.Dب \& Dines, D.E. (1968) Chronic nitrofurantoin pulmonar reaction: report of five cases. New England Journal of Medicine, 279, 1258.

SARKANY, I. (1967) Lymphocyte transformation in doxuge hypersensitivity. Lancet, i, 743. 